\title{
PENGARUH KONSENTRASI SURFAKTAN DAN PERBANDINGAN VOLUME EMULSI DENGAN VOLUME FASA EKSTERNAL PADA EKSTRAKSI ION MERKURI MENGGUNAKAN TEKNIK EMULSI MEMBRAN CAIR
}

\author{
The Effect of Surfactant's Concentration and Ratio of Emulsion Volume with External Phase \\ Volume on Extraction of Mercury Ion using the Emulsion Liquid Membrane Technique
}

\author{
*Nurul Hidayah, Baharuddin Hamzah, dan Purnama Ningsih \\ Pendidikan Kimia/FKIP - Universitas Tadulako, Palu - Indonesia 94118
}

Received 08 June 2017, Revised 10 July 2017, Accepted 10 August 2017

\begin{abstract}
Mercury ion extraction has been done using emulsion liquid membrane technique a research. The aim of this study is to determine the optimal conditions at the extraction process of mercury ion with research variables, namely variations of the surfactant concentration and the volume ratio of emulsion and external phase $\left(V_{e}: V_{\text {eks }}\right)$. In this study, the sample was $20 \mathrm{mg} / \mathrm{L}$ of $\mathrm{Hg}^{2+}$ ions in concentration. The concentration of mercury ions remaining in the sample after extraction were analysed using a UV-Vis Spectrophotometer at a wavelength of $490 \mathrm{~nm}$ using ditizon as complexation. The optimum condition far varying concentrations surfactant was $2 \%$ and the volume ratio of emulsion $\left(V_{e}\right)$ and external phase $\left(V_{\text {eks. }}\right)$ was $1: 5$ with the percentage of extraction respectively $47.65 \%$ and $56.80 \%$.
\end{abstract}

Keywords: extraction of mercury ion, emulsion liquid membrane, effect, surfactant, emulsion, external phase.

\section{Pendahuluan}

Pencemaran suatu lingkungan oleh ion logam berat selalu menjadikan masalah bagi negara-negara berkembang seperti Indonesia, sehingga sangat penting untuk memonitor keberadaan ion logam berat dalam lingkungan. Salah satu ion logam berat yang berbahaya bagi kesehatan adalah merkuri $(\mathrm{Hg})$. Banyak industri yang menggunakan raksa atau merkuri, sebagai contoh, pabrik plastik, pabrik sabun, kosmetika, penambal gigi dan fungisida. Di antara industri tersebut, masih banyak juga yang pembuangan limbahnya belum memenuhi syarat, sehingga dapat menyebabkan terjadinya pencemaran lingkungan (Kristianingrum, 2007).

Di alam merkuri berasal dari kegiatan gunung berapi, rembesan-rembesan air tanah yang melewati daerah yang mengandung merkuri. Aktifitas manusia menambah konsentrasi merkuri di lingkungan meningkat, seiring dengan kemajuan teknologi dan pertambahan jumlah penduduk (Purnawan, dkk., 2013).

Untuk mengurangi ion merkuri atau raksa(II) di lingkungan telah dilakukan secara konvensional yang selalu menghasilkan limbah padat yang membutuhkan proses pengolahan kembali secara lebih lanjut menggunakan pereaksi secara berlebihan yang pada akhirnya akan menjadi pencemar yang baru (Chakravati, dkk., 2000). Selain cara konvensional, dapat pula dilakukan ekstraksi pelarut untuk memperoleh kembali logam-logam, namun pengolahan dengan ekstraksi pelarut kurang

*Korespondensi

Nurul Hidayah

Program Studi Pendidikan Kimia, Fakultas Keguruan dan IImu Pendidikan, Universitas Tadulako

e-mail: nurulhidayah310795@gmail.com

Published by Universitas Tadulako 2017 ekonomis dan kurang efisien karena menggunakan beberapa tahap ekstraksi.

Teknik pemisahan yang berkembang saat kini adalah teknik emulsi membran cair. Teknik ini memberikan jangkauan aplikasi yang luas dan potensial, karena mudah pengoperasiannya, biaya operasional yang relatif lebih murah dan efisien (tahap ekstraksi dan ekstraksi balik terjadi dalam satu tahap) dengan selektifitas yang tinggi (Gawronski \& Religa, 2007).

Membran cair merupakan fasa cair yang memisahkan (barrier) dua fasa cair lain yang tidak bercampur dengan fasa membran tersebut. Membran cair terdiri dari fasa cair hidrofobik yang membagi dua fasa cair hidrofilik atau fasa hidrofilik yang membagi dua fasa hidrofobik. Kedua fasa cair yang dipisahkan oleh membran cair masing-masing disebut fasa ekstemal (umpan/kontinyu) dan fasa internal. Fasa ekstemal mengandung zat (spesi) yang akan dipisahkan, sedangkan fasa internal mempakan fasa penerima zat tersebut setelah melewati membran cair (Rusdinasari \& Buchari, 2001)

Mekanisme transfer massa terjadi di dalam emulsi membran cair. Teransfer massa ini memiliki tiga mekanisme transfer massa di dalam emulsi membran cair, yaitu difusi. Difusi yang diikuti dengan reaksi dalam fasa internal dan difusi dengan reaksi dalam membran. Penelitian ini akan menggunakan mekanisme transfer massa melalui difusi dengan reaksi kimia dalam fasa membran. Mekanisme ini didasarkan pada reaksi yang terjadi antara ion logam, misalnya $\mathrm{M}^{2+}$ dengan pereaksi HR (zat pembawa) yang dilarutkan ke dalam membran (Gurel, dkk., 2005).

Mekanisme transfer difusi dengan reaksi kimia dalam fasa membran dapat dilihat pada Gambar 1. 


\begin{tabular}{|c|c|c|}
\hline Fasa Internal & Fasa Membran & Fasa Eksternal \\
\hline $2 \mathrm{H}^{+}$ & $2 \mathrm{HR}$ & $\mathrm{M}^{2+}$ \\
\hline $\mathrm{M}^{2+}$ & $\mathrm{MR}_{2}$ & $2 \mathrm{H}^{\dagger}$ \\
\hline
\end{tabular}

Gambar 1. Mekanisme transfer massa melalui difusi dengan reaksi kimia dalam fasa membrane

Dalam rangka pengembangan metode emulsi membran cair, maka akan diteliti apakah dengan menggunakan metode tersebut dapat mengekstraksi ion merkuri dengan hasil persentase ekstraksi yang baik. Dalam metode ini, variabel yang akan analisis yang mempengaruhi persen ekstraksi, yaitu pengaruh perbandingan volume fasa membran dan volume fasa internal, pengaruh lama waktu ekstraksi, pengaruh konsentrasi surfaktan, pengaruh perbandingan volume emulsi dan volume fasa eksternal, pengaruh konsentrasi benzoil aseton, pengaruh $\mathrm{pH}$ fasa eksternal, pengaruh konsentrasi $\mathrm{HCl}$ dalam fasa internal, dan pengaruh konsentrasi ion $\mathrm{Hg}^{2+}$ terhadap persentase ekstraksi ion merkuri.

Tulisan ini dimaksudkan untuk memberikan informasi mengenai pengaruh konsentrasi surfaktan dan perbandingan volume emulsi dengan volume fasa eksternal pada ekstraksi ion merkuri yang akan memberikan persen ekstraksi terbesar.

\section{Metode}

\section{Alat}

Alat-alat yang digunakan dalam penelitian ini meliputi: gelas kimia, labu ukur, pipet volume, karet penghisap, neraca digital $A N D G R-200$, pipet tetes, corong pisah, statif dan klem, spatula, batang pengaduk, gelas ukur, wadah plastik, $\mathrm{pH}$ meter Lamotte, Cimarec Stirring and Hot Plate, magnetic stirrer dan spektrofotometer UV-VIS Perking Elmer Lamda 25.

\section{Bahan}

Bahan-bahan yang digunakan dalam penelitian ini meliputi: kristal $\mathrm{HgCl}_{2}$ (E. Merck), benzoil aseton (Merck Schuchardt OHG), span-20 (Merck Schuchardt $(O H G)$ dan span-80 (Merck Schuchardt OHG), kerosen, aquades, asam klorida (Merck) dan ditizone dalam $\mathrm{CCL}_{4}$

\section{Prosedur Kerja}

Penelitian ini menggunakan bahan sebagai berikut, berupa asam klorida, fasa membran berupa larutan benzoil aseton dalam kerosen yang mengandung surfaktan (campuran span 20 dan span 80) dan fasa eksternal yaitu kristal $\mathrm{HgCl}_{2}$. Dalam hal ini, variabel yang diteliti telah dimodifikasi dari penelitian yang telah dilakukan oleh Alam (2014).
Pengarub konsentrasi surfaktan terhadap persen ekstraksi ion merkuri(II)

Sampel ion merkuri dibuat dengan cara mencampurkan $30 \mathrm{~mL}$ emulsi yang ditambahkan ke dalam $210 \mathrm{~mL}$ larutan merkuri $20 \mathrm{ppm}$ dengan $\mathrm{pH}$ 3. Dimana, emulsi dibuat melalui pencampuran fasa membran (yang mengandung $0,015 \mathrm{M}$ benzoil aseton dan surfaktan campuran dengan konsentrasi surfaktan yang divariasikan, yaitu $1 \%, 2 \%, 3 \%, 4 \%$ dan $5 \%$ ) dan fasa internal dengan perbandingan volume $2: 2$ dengan kecepatan emulsifikasi menggunakan skala 10 selama 10 menit.

Proses ekstraksi dilakukan dengan kecepatan pengadukan pada skala 1,5 selama 10 menit. Setelah ekstraksi, fasa eksternal dipisahkan dari emulsi dan diukur konsentrasi ion merkuri menggunakan spektrifotometer UV-VIS. Konsentrasi surfaktan yang akan digunakan untuk percobaan selanjutnya adalah konsentrasi surfaktan yang memberikan persen ekstraksi terbesar.

\section{Pengaruh perbandingan volume emulsi dan volume fasa eksternal terhadap persen ekstraksi ion merkuri}

Proses ekstraksi dilakukan sama seperti perlakuan sebelumnya, hanya saja menggunakan konsentrasi surfaktan dengan hasil yang diperoleh pada percobaan sebelumnya yang memberikan persen ekstraksi terbesar, yaitu pada konsentrasi $2 \%$. Selain itu, pada perlakuan ini perbandingan volume emulsi dan volume fasa eksternal divariasikan yakni 1:5, 1:6, 1:7 dan 1:8.

\section{Analisis kandungan merkuri yang tersisa pada fasa eksternal}

Sampel hasil ekstraksi dari masing-masing variabel diencerkan dengan akuades hingga pengenceran 30 kali. Sampel hasil pengenceran kemudian ditambahkan $5 \mathrm{~mL}$ larutan ditizone $0,001 \%$ dalam $\mathrm{CCl}_{4}$ (suasana asam) kemudian diaduk secara perlahan hingga diperoleh warna yang stabil. Larutan yang terbentuk terdiri dari dua lapisan sehingga perlu dipisahkan menggunakan corong pisah. Fasa yang dianalisis merupakan fasa organik yang berwarna orange. Larutan standar yang digunakan terdiri dari beberapa konsentrasi yaitu larutan $\mathrm{Hg}$ (II) 0,15 ppm; $0,25 \mathrm{ppm} ; 0,35 \mathrm{ppm}$ dan $0,5 \mathrm{ppm}$. Penentuan konsentrasi sampel didasarkan pada persamaan regresi deret standar menggunakan instrumen spektrofotometer UV-Vis pada panjang gelombang $490 \mathrm{~nm}$ (Cahayani, 2014).

\section{Hasil dan Pembahasan}

Membran cair emulsi dibuat dengan membentuk emulsi dari dua fasa cair yang tidak saling campur dan kemudian emulsi yang terbentuk didispersikan ke fasa eksternal. Fasa eksternal mengandung spesies yang akan dipisahkan sedangkan fasa internal merupakan fasa penerima spesies yang telah dipisahkan setelah melewati membran cair (Bartsch \& Way, 1996). Untuk menstabilkan emulsi, selama proses ekstraksi 
ditarnbahkan surfaktan yang berfungsi untuk menurunkan tegangan pada bidang antarrnuka dari setiap fasa (Prayitno, dkk., 2000).

Analisis secara spektrofotometer $U V$-Visible harus menggunakan larutan yang memenuhi untuk absorpsi sinar tampak. Syarat larutan tersebut, yaitu harus berwarna. Dimana, larutan cuplikan yang tidak berwarna dibuat berwarna dengan menambahkan suatu zat atau pereaksi yang dapat menghasilkan warna atau biasa disebut zat pengompleks (Kristianingrum, 2010). Hal ini juga dilakukan dalam analisis $\mathrm{Hg}(\mathrm{II})$, dimana larutan cuplikan ditambahkan dengan zat pengomplek yaitu ditizon dalam $\mathrm{CCl}_{4}$.

Reaksi antara ion $\mathrm{Hg}^{2+}$ dengan zat pengompleks ditizon (HDz) akan menghasilkan senyawa kompleks merkuri ditizonat yang berwarna orange dan dapat dianalisis secara spektrofotometri UV-Visible. Struktur senyawa merkuri ditizonat ditunjukan pada Gambar 2.

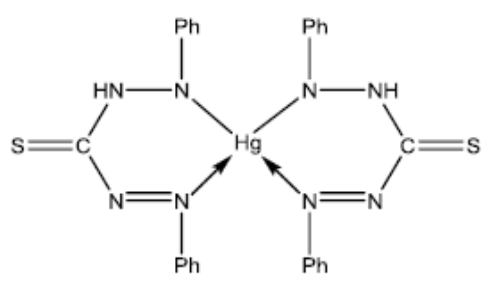

Gambar 2. Struktur senyawa kompleks merkuri ditizonat

Larutan kompleks berwarna orange yang diperoleh, selanjutnya dianalisis menggunakan sperktrofotometer UV-Visible pada panjang gelombang $490 \mathrm{~nm}$ (Prastiva, 2014). Penentuan konsentrasi sampel nantinya akan didasarkan pada persamaan regresi dari deret absorbansi larutan standar.

\section{Pengaruh konsentrasi surfaktan terhadap persen ekstraksi ion merkuri(II)}

Kondisi optimum pada variabel sebelumnya yang memberikan persen ekstraksi terbesar yang diperoleh pada perbandingan volume fasa membran dengan fasa internal yaitu 2:2 dan keadaan optimum lama waktu ekstraksi yang telah diperoleh sebelumnya, yaitu 10 menit. Perbandingan volume fasa membran dengan fasa internal dan lamanya waktu ekstraksi ini selanjutnya digunakan pada pembuatan emulsi untuk melihat pengaruh konsentrasi surfaktan. Variasi konsentrasi yang digunakan, yaitu 1\%, 2\%, 3\%, 4\% dan 5\%. Sampel hasil ekstraksi selanjutnya diencerkan menggunakan aquades kemudian dikomplekskan menggunakan zat pengompleks ditizon yang menghasilkan warna orange, sehingga dapat terukur absorbansinya. Nilai absorbansi yang diperoleh selanjutnya digunakan untuk menentukan konsentrasi sempel dan persen ekstrasi. Berdasarkan data yang telah diolah menggunakan nilai absorbansi, diperoleh data persen ekstraksi ion merkuri dengan variabel pengaruh konsentrasi surfaktan terhadap persen ekstraksi ditunjukan pada Gambar 3.

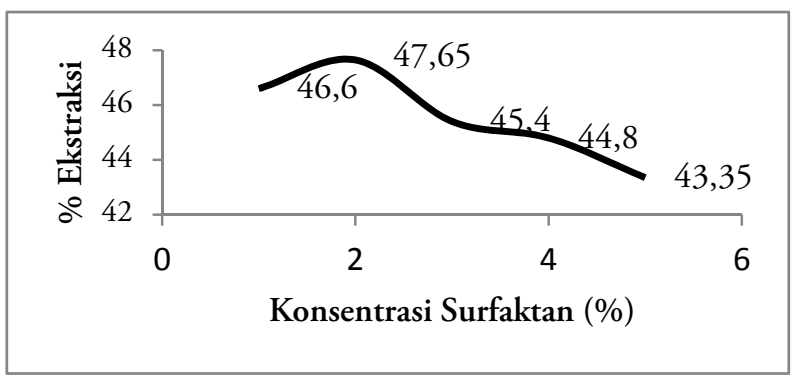

Gambar 3. Grafik pengaruh Konsentrasi Surfaktan terhadap Persen Ekstraksi Hg(II)

Surfaktan berfungsi untuk menurunkan tegangan permukaan. Tegangan permukaan akan turun dengan bertambahnya konsentrasi surfaktan dalam fasa membran sampai pada suatu konsentrasi tertentu, peningkatan konsentrasi surfaktan lebih lanjut tidak dapat menurunkan tegangan permukaan secara berarti. Surfaktan yang terlalu banyak dalam membran akan meningkatkan viskositas emulsi, sehingga dapat memperlambat difusi kompleks dalam fasa membran. Idealnya, diinginkan suatu emulsi yang stabil dengan kekentalan yang sekecil mungkin (Hamzah, dkk., 2011).

Berdasarkan grafik yang ditunjukkan pada Gambar 3 di atas, terlihat bahwa variasi konsentrasi surfaktan yang telah mencapai keadaan optimal dan memberikan persen ekstraksi terbesar yaitu pada konsentrasi 2\% dengan persen ekstraksi yang dihasilkan, yaitu sebesar 47,65\%. Hal ini dikarenakan tidak adanya transfer fasa eksternal ke fasa membran atau sebaliknya, yang menyebabkan pemisahan fasa eksternal dapat teipisah dengan sempurna terhadap fasa membran. Dengan demikian maka kestabilan membran relatif baik dibandingkan yang lain (Basuki dkk.,1995). Melihat hasil penelitian, persen ekstraksi ion merkuri meningkat dengan bertambahnya konsentrasi surfaktan dalam fasa membran, yaitu dari $1 \%$ hingga 2\%. Pada saat konsentrasi surfaktan $1 \%$ emulsi yang terbentuk kurang stabil sehingga persen ekstraksi yang dihasilkan kecil. Namun, pada saat konsentrasi surfaktan dinaikkan menjadi $2 \%$ persen ekstraksi meningkat. Hal ini disebabkan peningkatan konsentrasi surfaktan menyebabkan turunnya tegangan permukaan antara air dan kerosen sehingga diperoleh emulsi yang makin stabil, sedangkan konsentrasi surfaktan diatas $2 \%$ terjadi penurunan persen ekstraksi. Hal ini disebabkan surfaktan yang terlalu banyak dalam fasa membran akan meningkatkan viskositas emulsi sehingga dapat memperlambat difusi kompleks dalam fasa membran. Sebab, idealnya diinginkan suatu emulsi yang stabil dengan kekentalan yang sekecil mungkin, karena semakin kecil pemecahan emulsi semakin stabil pula emulsi tersebut. Sehingga dengan semakin tidak stabilnya emulsi, praktis tidak meningkatkan persen ekstraksi ion $\mathrm{Hg}(\mathrm{II})$ melainkan menurunkan persen ekstraksi ion $\mathrm{Hg}$ (II) (Hamzah et al., 2011). 
Pengaruh perbandingan volume emulsi dan volume fasa eksternal terhadap persen ekstraksi ion merkuri

Kondisi optimun pada variabel sebelumnya yang memberikan persen ekstraksi tersbesar diperoleh pada konsentrasi $2 \%$. Konstrasi ini selanjutnya digunakan pada pembuatan emulsi untuk melihat pengaruh perbandingan volume emulsi dengan volume fasa eksternal. Perbandingan volume emulsi dan volume fasa eksternal yang digunakan, yaitu 1:4, 1:5, 1:6, 1:7 dan 1:8. Sampel hasil ekstraksi selanjutnya diencerkan menggunakan aquades kemudian dikomplekskan menggunakan zat pengompleks ditizon yang menghasilkan warna orange, sehingga dapat terukur absorbansinya. Nilai absorbansi yang diperoleh selanjutnya digunakan untuk menentukan konsentrasi sempel dan persen ekstrasi. Berdasarkan data yang telah diolah menggunakan nilai absorbansi, diperoleh data persen ekstraksi ion merkuri dengan variabel pengaruh konsentrasi surfaktan terhadap persen ekstraksi ditunjukan pada Gambar 4.

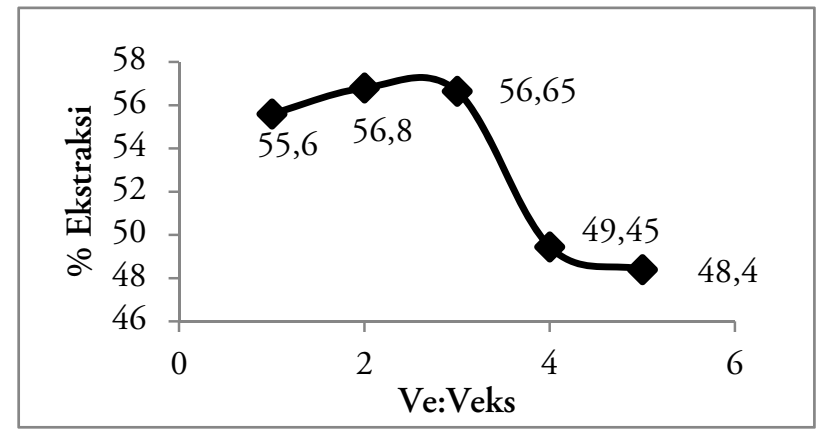

Gambar 4. Grafik pengaruh $\mathrm{V}_{\mathrm{e}}: \mathrm{V}_{\text {eks }}$ terhadap persen ekstraksi $\mathrm{Hg}(\mathrm{II})$

Berdasarkan grafik yang ditunjukkan pada Gambar 4, terlihat bahwa perbandingan $\mathrm{V}_{\mathrm{e}}: \mathrm{V}_{\text {eks }}$ yang memberikan persen ekstraksi terbesar yaitu 1:5 dengan persen ekstraksi sebesar 56,8\%. Pada grafik terlihat bahwa persen ekstraksi meningkat dari perbandingan $\mathrm{V}_{\mathrm{e}}: \mathrm{V}_{\text {eks }}$ 1:4 hingga 1:5 dan menurun seiring dengan bertambahnya volume fasa eksternal, sehingga dengan demikian dapat disimpulkan bahwa semakin bertambahnya volume fasa eksternal yang digunakan pada analisis merkuri memperkecil persen ekstraksi yang dihasilkan. Hal ini disebabkan karena pada dasarnya perbandingan antara $\mathrm{V}_{\mathrm{e}}: \mathrm{V}_{\mathrm{eks}}$ dapat meningkatkan laju ekstraksi, namun penggunaan $\mathrm{V}_{\mathrm{e}}: \mathrm{V}_{\text {eks }}$ yang kurang dari 1:5 fasa internal yang terdapat pada emulsi belum mencapai konsentrasi setimbangnya karena pada perbandingan 1:4 volume emulsi lebih banyak jumlahnya dibandingkan sampel pada fasa eksternal yang menyebabkan proses ekstraksi tidak berlangsung dengan baik sehingga persen ekstraksi yang dihasilkan kecil, namun pada saat perbandingan $V_{e}: V_{\text {eks }}$ yang lebih besar dari 1:5, ternyata relatif tidak memberikan peningkatan persen ekstraksi ion merkuri pula bahkan persen ekstraksi cenderung semakin berkurang. Hal ini disebabkan karena jumlah fasa internal yang terdapat dalam emulsi tidak cukup untuk menampung seluruh ion merkuri yang terdapat dalam fasa eksternal. Pada perbandingan 1:5 ion merkuri telah mencapai konsentrasi kesetimbangannya di dalam fasa internal sebelum seluruh ion merkuri berpindah dari fasa eksternal ke fasa internal. Kerena pada dasarnya bertambahnya jumlah emulsi dapat berperan terhadap peningkatan pemecahan emulsi, akibatnya persen ekstraksi akan berkurang (Chiha, dkk., 2006).

\section{Kesimpulan}

Konsentrasi surfaktan yang memberikan persen ekstraksi terbesar pada proses ekstraksi ion merkuri menggunakan teknik emulsi membran cair, yaitu pada konsentrasi $2 \%$ dengan persen ekstraksi $(\% \mathrm{E})$ sebesar $47,65 \%$. Perbandingan volume emulsi dengan volume fasa eksternal yang memberikan persen ekstraksi terbesar pada proses ekstraksi ion merkuri menggunakan teknik emulsi membran cair, yaitu pada perbandingan 1:5 dengan persen ekstraksi $(\% \mathrm{E})$ sebesar $56,80 \%$.

\section{Ucapan Terima Kasih}

Ucapan terima kasih penulis sampaikan kepada teman-teman atas bantuan yang diberikan. Penulis juga menyampaikan ucapan terima kasih kepada Husnia, Nurbaya dan Tasrik laboran di Laboratorium Kimia FKIP Universitas Tadulako.

\section{Referensi}

Alam, S. (2014). Penentuan kondisi optimum ekstraksi ion timbal(II) menggunakan teknik emulsi membran cair. Skripsi. Palu: Universitas Tadulako.

Bartsch, R. A., \& Way, J. D. (1996). Chemical separations with liquid membranes. ACS Symposium Series, 642, 1-2.

Basuki, K. T., Sudibyo, R., Bambang, E. H. B., \& Muhadi, A. W. (1995). Ektraksi uranium dengan proses membran emulsi memakai ekstraktan tributdlfosfat. Prosiding Pertemuan dan Presentasi Ilmiah PPNY-BATAN, 37-44.

Cahayani, A. D. (2014). Pengujian metode spektrofotometri uv-vis untuk penentuan $\mathrm{Hg}$ (II) dalam limbah cair laboratorium FMIPA UGM dengan pereaksi ditizon. Yogyakarta: Universitas Gadjah Mada.

Chakravati, A. K., Chowdhdury, S. B., \& Mukherjee, D. C. (2000). Liquid membrane multiple emulsion process of separation of copper(II) from waste waters. Colloids and Surfaces, $A$ Physiochemical and Engineering Aspects, 166(1-3), 7-25.

Chiha, M., Samar, M. H., \& Hamdaoni, O. (2006). Extraction of chromium(VI) from sulphuric acid aqueous solutions by a liquid surfactant membrane. Desalination, 194(2), 69-80. 
Gawronski, R., \& Religa, P. (2007). Transport mechanism of chromium(III) through the unmixed bulk liquid membrane containing dinonylnaphthalenesulphonic acid as a carrir. Journal of Membrane Science, 289(1-2), 187-190.

Gurel, L., Altas, L., \& Buyukgungor, H. (2005). Removal of lead from wastewater using emulsion liquid membrane technique. Environmental Engineering Science, 22(4), 411-420.

Hamzah, B., Jalalauddin, N., Wahab, A. W., \& Upe, A. (2011). Pengaruh ion kadmium(II) dan nikel(II) pada ekstraksi ion tembaga(II) dengan ekstraktan 4-benzoil-1-fenil-3-metil-2-pirolizin5-on-menggunakan emulsi membran cair. Jurnal Natur Indonesia, 13(3), 269-275.

Kristianingrum, S. (2007). Modifikasi metode analisis spesiasi merkuri dalam lingkungan perairan. Prosiding Seminar Nasional Penelitian, Pendidikan dan Penerapan MIPA Yogyakarta, 72-75.
Prastiva. (2014). Analisis ion Hg(II) dalam krim pemutih secara spektrofotometri UV-vis. Skripsi. Yogyakarta: Universitas Gadjah Mada.

Prayitno, Sardjono, D., \& Hakim, L. (2000). Penurunan kadar merkuri pada limbah cair dengan teknik membran emulsi cair. Puslitbang Keselamatan Radiasi dan Biometika NuklirBatan, 11-20.

Purnawan, S., Sikanna, R., \& Prismawiyanti. (2013). Distribusi logam merkuri pada sedimen laut di sekitar muara sungai poboya. Online Jurnal of Natural Science, 2(1), 18-24.

Rusdinasari, \& Buchari, D. (2001). Ekstraksi uranium dari limbah cair artifisian dengan membran cair aliran kontinyu. Risalah Pertemuan Ilmiah Penelitian dan Pengembangan Aplikasi Isotop dan Radiasi, 143-148. 